\title{
O CONTROLE SOCIAL POR MEIO DA TRANSPARÊNCIA ATIVA E PASSIVA NO ENFRENTAMENTO À CORRUPÇÃO
}

http://dx.doi.org/10.21527/2176-6622.2021.56.9489

Recebido em: 10/9/2019

Aceito em: 20/1/2020

Ana Paula Cordeiro Krug

Autora correspondente. Faculdade Dom Alberto. Rua Ramiro Barcelos, 892, Centro. Santa Cruz do Sul/RS, Brasil. CEP 96810-054. http://lattes.cnpq.br/2311823741618849. http://orcid.org/0000-0001-5203-6505.

anapkrug@hotmail.com

Rogério Gesta Leal

Universidade de Santa Cruz do Sul. Santa Cruz do Sul/RS; Faculdade de Direito da Fundação Escola Superior do Ministério Público. Porto Alegre/RS, Brasil. http://lattes.cnpq.br/7185339028226710. https://orcid.org/00000003-1372-6348. gestaleal@gmail.com

\section{RESUMO}

O presente trabalho tem como tema a transparência ativa e passiva como ferramenta ao exercício do controle social em um Estado Democrático de Direito à luz da cidadania participativa e da Lei de Acesso à Informação. Como problema central o seguinte questionamento: Considerando-se a prerrogativa do Estado Democrático de Direito, a efetividade da Lei de Acesso à Informação tem fim em si mesma para o exercício do controle social como forma de enfrentamento à corrupção? Propõe-se como objetivos demonstrar a importância da cidadania participativa na concepção de um Estado Democrático de Direito; identificar se a Lei de Acesso à Informação é uma forma direta de exercício do controle social e analisar os desafios e efetividade da Lei de Acesso à Informação após sua entrada em vigor em relação ao cumprimento das exigências dos parâmetros da transparência e de enfrentamento à corrupção. Para isso, usou-se como parâmetro os dados dos relatórios disponibilizados pelo Tribunal de Contas do Rio Grande do Sul, 2018 e 2019, em relação aos municípios do Estado. A metodologia utilizada foi a bibliográfica, além de visitação no site do Tribunal de Contas do Rio Grande do Sul. Desse modo, conclui-se que a transparência ativa e passiva são ferramentas de meio para efetivar o controle social e, com efeito, formas de inibir a prática da corrupção na gestão pública.

Palavras-chave: Controle social; corrupção; transparência.

\section{SOCIAL CONTROL THROUGH ACTIVE AND PASSIVE TRANSPARENCY IN COPING WITH CORRUPTION}

\section{ABSTRACT}

The present work has as its theme the active and passive transparency as a tool for the exercise of social control in a democratic state of law in the light of participatory citizenship and the law of access to information. As a central problem the following question: Considering the prerogative of the democratic State of law, does the effectiveness of the law of Access to information have an end in itself for the exercise of social control as a way of coping with corruption? It aims to demonstrate that the importance of participatory citizenship in the conception of a democratic state of law; To identify whether the access to Information Act is a direct way of exercising social control; and analyze the challenges and effectiveness of the access to Information Act after its entry into force in relation to compliance with the requirements of the parameters of transparency and coping with corruption. For this, we used as a parameter the data from the last report made available by the Court of Auditors of Rio Grande do Sul in relation to the municipalities of the state. The methodology used was the bibliography, and also used the visitation process on the website of the Court of Auditors of Rio Grande do Sul. Thus, it is concluded that active and passive transparency are tools of means to effectise social control and, in effect, to inhibit the practice of corruption in public management.

Keywords: Social control; corruption; transparency. 


\section{INTRODUÇÃO}

O presente trabalho tem como finalidade principal analisar, no âmbito do Estado Democrático de Direito, o exercício do controle social à luz da Lei de Acesso à Informação como forma de enfrentamento à corrupção. $\mathrm{O}$ artigo busca uma resposta à seguinte problematização: Considerando-se a prerrogativa do Estado Democrático de Direito, a efetividade da Lei de Acesso à Informação tem fim em si mesmo para o exercício do controle social como forma de enfrentamento à corrupção?

Para tanto, usou-se como parâmetro os dados dos últimos dois relatórios disponibilizados pelo Tribunal de Contas do Rio Grande do Sul em relação aos municípios do Estado.

De início, aborda-se aspectos teóricos de democracia, bem como o histórico e efetividade da Lei de Acesso à Informação para o exercício do controle social. Após, foi realizada análise quanto às formas de controle social que estão à disposição para repressão da corrupção.

Finalmente, diante desta análise e alcançando a resposta do problema, tem-se como objetivo verificar se em uma perspectiva de Estado Democrático de Direito identifica-se a Lei de Acesso à Informação como uma forma direta de exercício do controle social e consequentemente forma de combate à corrupção. $O$ método de abordagem é o bibliográfico.

\section{EVOLUÇÃO HISTÓRICA DA DEMOCRACIA}

A sociedade - e não é de hoje - anseia por maior estabilidade na democracia, sempre repensando o momento atual para que se possa adquirir uma participação democrática.

O discurso da democracia surge em Atenas, Grécia Antiga, em meados dos séculos 4 e 5o (a.C), quando nasce o termo democracia direta. $O$ entendimento era de que o cidadão poderia participar de forma direta da política, ou seja, nem todo indivíduo e sim aquele considerado cidadão.

À época, faziam parte deste seleto grupo os homens atenienses livres e adultos. De forma bem limitada, os considerados cidadãos, acompanhados dos governantes, reuniam-se em assembleia para discutir a política (PEDROSA, 2010). A democracia ateniense é a mais antiga forma de exercício da cidadania, em que pese fosse um privilégio de poucos daquela época

À medida que a sociedade foi evoluindo, as concepções de democracia foram se alterando. Modelo variado da democracia é a denominada indireta, ou representativa, caracterizando-se pelo exercício do poder por representantes do povo, eleitos pelo voto, ou seja, não existe nesse modelo a participação direta, mas intermediada por outras pessoas eleitas para atuarem de tal modo (BOBBIO, 2004).

Nessa modalidade de democracia, exercida mediante o sufrágio universal, elege-se um representante do povo para assegurar as intenções populares. Cada vez mais, contudo, parece-nos que o candidato, após eleito, rompe o elo com seu eleitor, tomando decisões que favorecem a si próprio ou aos seus interesses (BONAVIDES, 2001).

Bobbio (2004), por sua vez, defende modelo diverso de democracia, uma espécie de concepção de integração da direta e da representativa, denominada semidireta ou participativa, na qual o povo elege seus representantes, todavia detém direito à participação, considerando o entendimento de que um estilo de democracia não impede o outro, não sendo alternativos.

Doutrina Bonavides (2001) que não há que se falar em democracia que não a democracia participativa, ao passo que a Constituição Federal de 1988 alcança inarredável poder à soberania popular, que somente se potencializará com o desprendimento do modelo representativo democrático.

A democracia participativa, em um conceito generalizado, revela-se como a participação do povo nas três esferas do poder, abarcando a sociedade como um todo.

Bonavides (2001) apregoa que a hermenêutica de impossibilidade de concretização da democracia direta se sustentaria em tempos passados. Doutrina, todavia, que em tempos de tecnologias desenvolvidas e conduzidas pela Informática, a justificativa de "extensão do Estado" cai por terra, posto que o acesso à informação e a possibilidade de participação do cidadão se perfectibiliza. Bonavides não afasta, no entanto, inte- 
gralmente o sistema representativo, sustentando sua utilização de forma instrumental, sujeitando à soberania da decisão popular, como forma de controle final do processo político.

Essa possibilidade de efetiva participação popular fica evidente em uma análise ao artigo 1으, parágrafo único, e artigo 14, ambos da Lei Maior, posto que expressamente enunciado o exercício da soberania popular, em especial pela possibilidade de participar por meio de plebiscito, referendo e iniciativa popular. A crítica é no sentido de que na prática não há efetiva participação popular ante o evidente bloqueio por parte das elites do poder (BONAVIDES, 2001).

Esta crítica resta evidente quando se analisa que a efetiva participação não é sinônimo de ação continuada e sim esporádica, como exemplos práticos dispomos do plebiscito de 1994 para votar entre monarquia, parlamentarismo ou presidencialismo, e em 2006 o referendo sobre o Estatuto do Desarmamento.

Habermas, que defende a teoria da democracia deliberativa, indica que fazer democracia seria tomar decisões racionais. Argumenta Habermas que nesta teoria os indivíduos, por deliberação, ou seja, troca de argumentos, participam de processos comunicativos, trabalhando com três argumentos: autointeresse, ética e moral universal. Nesse sentido, ser racional significa deliberar, trocar argumentos. Este autor propôs a democracia deliberativa como democracia ideal (BITENCOURT; RECK, 2017).

Bitencourt e Reck (2018, p. 136-138) lecionam sobre a aproximação entre informação e democracia deliberativa, assim destacando:

Outro fator fundamental deste estreitamento entre informação e democracia, especialmente a deliberativa, está no papel decisivo para a formação e para a análise da eficácia das políticas. $O$ ideal de legitimidade democrática é aquele que atende aos pressupostos dessa ação comunicativa, ou seja, a autorização para exercer o poder estatal necessita emergir das decisões coletivas dos integrantes dessa sociedade que dialoguem entre si, pois serão diretamente afetados pelo exercício daquele poder; por isso, necessita haver a interlocução.

A inarredável e indispensável utilização da Internet acabou absorvida inclusive pelas necessidades democráticas, sendo amplamente utilizada no voto por meio de urnas eletrônicas, e-governo, campanhas políticas e especialmente a transparência da gestão pública. Nesse cenário, um novo campo de oportunidades para retomada da efetiva participação civil nas decisões emanadas da esfera política ganha força.

Ganha importante impulso, igualmente, o controle social, que conforme conceituado pela Controladoria Geral da União - CGU (CONTROLADORIA..., 2019), trata-se da efetiva participação do cidadão na gestão da máquina pública, em especial na luta contra a tão odiada corrupção, contribuindo para uma correta aplicação dos recursos públicos, visando ao efetivo atendimento às necessidades da sociedade, tornando-se um complemento àquele controle institucional, exercido pelos órgãos fiscalizadores.

\section{CORRUPÇÃO E DESENVOLVIMENTO DE FERRAMENTAS DE CONTROLE SOCIAL}

A corrupção é uma antiga prática que existe desde os primórdios das sociedades. Relatos de abuso do poder para obtenção de vantagens indevidas sempre existiram ao longo da História, e no Brasil não foi diferente, estando intimamente atrelada tanto ao poder político quanto ao econômico, ante a relação de proximidade entre ambos (PÉREZ, 2014).

Importante salientar que o termo "corrupção" engloba uma gama de infrações que vão além das transgressões penais, alcançando as esferas civis e administrativas. Por isso, em que pese a corrupção seja uma antiga conhecida na sociedade, não deixa de ser emblemática, pois detém múltiplos significados, o que dificulta sua definição (SIMÃO NETO, 2014).

Segundo Gómes (2016), o termo corrupção, dentro da esfera pública, expressa-se por usar da função para benefício de gestores públicos. Quanto à falta de consenso na doutrina acerca da definição do que seja corrupção, Leal (2018, p. 479) aponta que:

O importante é que a definição do que seja corrupção permaneça como projeto inacabado, a uma, porque material e formalmente a criatividade para expandir os tentáculos da corrupção parece ser infindável; a duas, porque a pressão pública alimentada pelos sistemas de controles institucionais e sociais, somado ao papel das mídias, têm mostrado que a missão de combate à corrupção é permanente. 
Essa nova participação civil por meio de elementos digitais, conforme argumenta Gomes (2005), inova ao instituir um caminho alternativo entre a democracia direta e a democracia representativa, apresentando nova possibilidade ao modelo deliberativo.

Acerca dessas novas perspectivas para a participação popular na esfera de decisão política, Gómes (2016) salienta que "a internet parecia a terra prometida da participação tanto pelo que impedia quanto pelo que proporcionava". Nesse sentido, esclarece o autor que a nova ferramenta vem possibilitar a qualquer cidadão, indiferente de circunstâncias sociais, a relação direta com o Estado ou seu sistema político, sem a necessidade de depender do bom interesse de terceiros intermediários, como partidos políticos, corporações ou sindicatos. Pode o cidadão interessado, por meio da Internet, de forma livre e conforme seu interesse nas questões atinentes à política, buscar informações acerca da administração pública, formando opinião e com oportunidade de participação e engajamento no meio político.

Leal (2013) ressalta que a corrupção tem ganho notoriedade em razão da difusão da mídia, trazendo como aspectos positivos dessa transparência o fato de atingir a opinião pública em massa e resgatando valores de indignação.

Em meio a este quadro, com uma tarefa pró-democracia, com foco ainda nas desigualdades sociais e desenvolvimento econômico, o Brasil adota igualmente a questão da transparência, ante a evidente problemática da corrupção, conhecida destruidora da democracia, da legitimidade dos governos e da moral pública (PEREIRA, 2005).

A transparência está intimamente ligada ao princípio da publicidade dos atos da administração, princípio abarcado pela Constituição Cidadã, tendo como marco legal o disposto em seu artigo 37, mais pormenorizada no $§ 10$.

Nesta mesma senda, o parágrafo único do artigo 70 da Constituição de 1988 impõe aos gestores públicos a obrigatoriedade de exercerem a prestação de contas, servindo como maior amplitude ao alcance das legislações, buscando dar ênfase à participação civil na administração pública, visando justamente à transparência é o teor expressamente previsto na Emenda Constitucional no 19, de 4/6/1998.

O amplo exercício da transparência possibilita o acompanhamento da gestão pública por diferentes classes sociais, possibilitando as reivindicações de seus interesses e, ao passo que se efetiva esse controle social, o detalhamento e disponibilidade de informações tendem a se tornar mais claros e efetivos. A divulgação unicamente para grupos restritos ataca os próprios princípios constitucionais que lastreiam a democracia e desenvolve campo passível de condutas ilícitas. Ao efetivar a transparência de seus atos, a gestão pública possibilita o acesso dos cidadãos, com reivindicações de seus interesses (FIGUEIREDO; SANTOS, 2013).

Como meio de concretizar os esforços do Estado brasileiro para o fortalecimento da democracia por meio da participação civil, foi sancionada a Lei Complementar no 101/2000, Lei de Responsabilidade Fiscal, indo ao encontro das necessidades da gestão pública brasileira em específico, bem como dos anseios da sociedade, visando justamente a atribuir maior transparência à gestão pública.

Referida transparência resta evidente já no artigo 1ㅇ, $\$ 1$, da Lei Complementar 101/2000, ao tratar especificamente acerca da necessidade de se fazer transparentes as execuções da gestão fiscal, almejando a melhor eficiência, prevenindo e corrigindo esquemas de corrupção.

Em complemento, em 27 de maio de 2009 foi sancionada a Lei Complementar no 131, denominada Lei da Transparência na Gestão Pública, visando a um melhor entendimento e aplicação da Lei de Responsabilidade Fiscal, trazendo importantes alterações.

Entre as alterações, destaca-se que anteriormente à Lei Complementar no 131, a transparência era tida como um "incentivo" à participação popular. Após promulgada a Lei, no entanto, a transparência nos atos de gestão pública passa a ser obrigatória, não somente por meio de atos passíveis de participação dos cidadãos, mas também, e especialmente, por meio de publicação em plataforma na Internet.

Nessa evolução legislativa, mister, por derradeiro, frisar a promulgação da Lei no 12.527, de 18 de novembro de 2011 - Lei de Acesso à Informação (LAI) - com entrada em vigor no ano de 2012, ampliando a transparência de gestão dos três poderes, da União, Estados, Distrito Federal e municípios, regulamentando o já constitucional direito à informação e, como leciona Moraes (2012, p. 298), ratificando o caráter de publi- 
cidade como regra e o sigilo como exceção, promovendo a transparência e controle social da gestão pública, combatendo processos arbitrariamente sigilosos.

A Constituição Brasileira de 1988 consignou ideais além de seu tempo, uma vez que naquela época não era possível decifrar de que forma seriam garantidos os direitos ali positivados. Com ideologias totalmente contrárias à então recente ditadura vivida, garantiu direitos como acesso à informação, mas como em diversas outras garantias muito tempo se passou para criar instrumentos para efetivamente alcançar tais direitos.

Em que pesem dispositivos constitucionais que gozavam do direito de acesso à informação, bem como a Lei de Responsabilidade Fiscal, Lei de Habeas Data, Portal da Transparência, faltava uma legislação específica que desse conta de regularizar os dispositivos constitucionais.

Com este intuito, mais de 20 anos após a promulgação da Carta Política atual, é sancionada a Lei no 12.527/2011. Isso deve-se à pressão e ao debate internacional na esfera de direitos civis e políticos, aliados ao combate à corrupção. Aliás, o emprenho no combate à corrupção, visível pelos inúmeros protestos da população nos últimos anos, é um dos motivos da crescente busca pela transparência.

Verifica-se que no Brasil existem sites governamentais e não governamentais de acesso à transparência ativa e passiva. Não podemos declinar o sentimento de falta de efetivação ou gestão dos serviços e políticas públicas à ausência de legislação. Em nosso país, ainda mais ardil a tarefa de desenvolver uma cultura de motivação social, até em razão do histórico político perturbado vivenciado no Brasil, em que a cultura do sigilo era a regra. Para contrapor este ideal de segredo, o texto constitucional contém vários dispositivos que garantem a participação cidadã nas deliberações de gestão pública.

Assim, destaca-se o posicionamento de Gruman quando destaca o caráter instrumental da LAI:

A transparência e o acesso não garantem a eficácia do funcionamento da máquina pública, mas, pelo contrário, sua ausência é garantia de mau uso dos recursos públicos porque livres de controle social. 0 acesso à informação é um instrumento, um meio para alcançar um fim, a eficácia das políticas públicas (GRUMAN, 2012, p. 104).

Estes sites são importantes ferramentas de aproximação governo-cidadãos, mas ainda estamos longe do nível ideal e de excelência, e isso vale para os três poderes: Executivo, Legislativo e Judiciário.

Inegável a evolução da transparência, segundo o relatório do Tribunal de Contas do Rio Grande do Sul divulgado em 2018 e denominado "Relatório da transparência ativa dos municípios gaúchos, avaliação realizada em 2017". No período de 2014 a 2017, nos municípios de mais de 10 mil habitantes, apresenta crescimento das médias de atendimento aos critérios da LAI de forma geral tanto no âmbito do Executivo quanto Legislativo municipal (TCE-RS, 2018).

O mesmo não acontece com os requisitos de registro de repasse ou transferências; dados gerais para acompanhamento de programas, ações, projetos e obras; Instrumento Normativo local que regulamente a LAl e demonstrativos contábeis, que ficaram com índices bem baixos de atendimento, média menor que $70 \%$ (TCE-RS, 2018).

É preciso ainda considerar, porém, que diante do último relatório do Tribunal de Contas, maio 2019, sobre a mesma temática, os números foram atualizados. Isso porque os municípios, por meio das prefeituras e Câmaras de Vereadores, encaminharam pedidos de revisão dos dados, o que acarretou em 4.376 itens corrigidos. Igualmente culminou resultados com crescimento nos índices de atendimento aos pontos avaliados, tais como: 9\% nos Legislativos com mais de 10 mil habitantes e 6\% nos Executivos com mais de 10 mil habitantes (TCE-RS, 2019).

Cabe mencionar que o relatório do TCE-RS leva em consideração a transparência ativa, com o que o fato de determinado município "estar atendendo à totalidade dos itens verificados pelo TCE-RS não significa que esteja cumprindo, necessariamente, com a integralidade de seus deveres legais relativos ao tema transparência" (TCE-RS, 2019).

Nesse sentido, em que pese se reconheça o aumento no cumprimento dos requisitos da LAl, tem-se que em pontos importantes os portais não correspondem ao fornecimento de informações de forma mínima, não se atingindo a transparência, tampouco possibilitando o controle social. 
Importa salientar que a divulgação destas informações mencionadas deve (deveria) estar disponível independentemente de requerimento, como preceitua o inciso II do § 10 do artigo 8 ㅇ da LAI.

Isso impacta sobremaneira na compreensão e controle do orçamento público, não sendo possível obter a informação de verbas públicas mínimas estipuladas pela Constituição Federal, como 15\% para a saúde e 25\% para a educação.

Na busca pela cultura do governo aberto, com objetivo de aproximar o cidadão das diversas instituições do Estado, entende-se como anseio da população não somente ser ouvido, ou seja, não apenas em um plano conceitual. Isso significa dizer que a população deseja não só participar, mas influenciar todo o processo decisório de gestão e políticas públicas.

Na concepção de Jacobi (2005) a participação é uma limitação à democracia representativa, possibilitando assim o controle social e formulação de políticas públicas, contudo o desafio deste controle são as barreiras criadas pelos órgãos públicos.

Para tanto é necessário que na sociedade civil surjam interlocutores coletivos desarticulados, mas motivados para o engajamento em práticas participativas - que viabilizem uma participação ativa e representativa, sem que o Estado exija nenhum tipo de dependência administrativa e financeira. Isso cria, portanto, as condições para romper com as práticas tradicionais - populismo, autoritarismo, clientelismo, assistencialismo, mandonismo, patrimonialismo e privatização da política nas suas diversas acepções (JACOBI, 2005, p. 31).

Ainda segundo o autor, o Estado deveria possibilitar a cidadania ampliada instrumentalizando a população e, para isso, precisaria "criar espaços democráticos e plurais de articulação e participação" (JACOBI, 2005, p. 33).

O controle social, que é exercido pela população, está previsto na própria LAl, e se traduz como a maior expressão da cidadania. Ensina Leal (2018, p. 19-20) sobre a importância da cidadania participativa:

Durante muito tempo a reação da cidadania diante da corrupção - em especial no Brasil - foi de indiferença, e não só dela, eis que as forças públicas de repressão do Estado também foram atingidas por desalentos relacionados às dificuldades de apuração dos atos corruptos, não só porque eram atividades muito furtivas e protegidas por grande número de interessados poderosos, mas também por causa da inexistência até pouco tempo de ferramentas jurídicas e administrativas capazes de serem mais eficientes no trato destas questões.

O cidadão dispõe de alguns artifícios para realizar a fiscalização das contas públicas, entre eles o exercício direto do poder, os conselhos de políticas públicas, os quais possuem função deliberativa ou consultiva, com formação de representantes do poder Executivo e de instituições da sociedade civil. Os Conselhos de Políticas Públicas constituem um importante instrumento de controle social e atos praticados pelos governantes, inclusive na captação de recursos. Quanto à abrangência, pode ser municipal, estadual ou nacional (CONTROLADORIA..., 2019).

Na seara municipal, pode-se citar o Conselho Municipal da Educação e o Conselho Municipal da Saúde, com atribuições de fiscalizar valores destinados à saúde e educação, mas principalmente participar na formulação de metas. Dessa forma, a população surge como protagonista do processo decisório dessas áreas tão importantes (CONTROLADORIA..., 2019).

Os observatórios sociais são instituições não governamentais que têm por finalidade a prevenção, tendo como missão estimular a própria população a exercer a fiscalização. Não se confunde com as funções do Tribunal de Contas, haja vista que é formado por cidadãos (OBSERVATÓRIO..., 2019).

E é por meio de política pública, neste caso pela LAI, que se busca efetivar o uso das ferramentas dispostas. Significa dizer que não obstante estas e outras ferramentas, sem transparência não se pode falar em controle social. Se a população desconhece estes mecanismos, igualmente não há que se falar em controle social, constituindo-se de suma importância a transparência das contas públicas para inibir a corrupção.

Até porque é emblemático descobrir os motivos que podem levar à falta de dados ou de clareza dos portais de transparência de forma ativa ou passiva. Não se espera encontrar respostas absolutas para as perguntas a seguir propostas, mas algumas possibilidades são possíveis: Seria a resistência do poder público em 
não divulgar? O gestor teme a divulgação de dados de seu órgão? A qualidade do que é divulgado? Desinteresse do cidadão em fiscalizar? A centralização dos dados facilitaria o acesso?

Gruman (2012, p. 100) orienta que “Muitos temas 'entram' no espaço público e se transformam em políticas públicas a partir da reivindicação da sociedade civil, através dos movimentos sociais, daí a importância da participação dos cidadãos".

Jacobi (2005) ensina que em uma esfera municipal deve-se ter diálogo e cooperação, ressaltando que deve haver um compartilhamento das alternativas. Por isso entende-se que a LAI, por si só, não é sinônimo de controle social, mas importante ferramenta de contribuição para tal. Ainda, segundo Bitencourt e Reck:

A informação é de extrema fundamentalidade ao controle da corrupção pública. Se se compreender a corrupção como uma forma de desvio, deturpação, degradação da coisa pública em sentido amplo, a corrupção passa a ser um sentido cuja fronteira é cruzada quando há a presença do patrimônio público em sentido amplo e a desigualdade (2018, p. 14).

Nesse sentido, afirmam Bitencourt e Reck que a informação tem papel fundamental para o combate de atividade corruptiva na gestão pública, bem como uma importante ferramenta para o controle social.

\section{CONCLUSÃO}

O presente artigo procurou responder ao seguinte problema: Considerando-se a prerrogativa do Estado Democrático de Direito, a efetividade da Lei de Acesso à Informação tem fim em si mesmo para o exercício do controle social como forma de enfrentamento à corrupção?

Para tanto, realizou-se pesquisa sobre a evolução histórica de democracia e evolução legislativa até se chegar à Lei de Acesso à Informação, no sentido de encontrar formas de repressão contra a corrupção, a qual contém múltiplos sentidos. Neste sentido, entendeu-se que o fenômeno da corrupção não se apresenta com uma conceituação facilmente delimitada.

Evidenciou-se, então, que tanto a transparência quanto o acesso à informação são ferramentas de meio e não de fim para concretizar o controle social, sendo forma de inibir a prática da corrupção na gestão pública por meio da atuação do controle social.

Admite-se que é emblemático descobrir os motivos que podem levar à falta de dados ou de clareza dos portais de transparência de forma ativa ou passiva, o que consequentemente abre portas para corrupção.

Como forma de enfrentamento a estas questões, o governo deve disponibilizar o exercício de participação popular, permitindo o acesso e a compreensão de como e onde está sendo aplicado o dinheiro público, para assim se efetivar a democracia e o controle social. Indo além, não basta que os dados e ações do poder público cheguem à população e sim que sejam compreendidos. Este desafio ainda é uma utopia.

O fato é que quanto mais transparente, mais eficiente a gestão do governo, mas a transformação se efetiva com a mobilização do povo, ou seja, talvez o caminho mais certo na busca pelo combate à corrupção seja por meio da cidadania participativa.

\section{REFERÊNCIAS}

BASTOS, Celso Ribeiro. Curso de direito constitucional. São Paulo: Saraiva, 2001.

BITENCOURT, Caroline Müller; RECK, Janriê Rodrigues. Democracia deliberativa, teoria da decisão e suas repercussões no controle social das despesas em saúde. Revista de Direito Econômico e Socioambiental, v. 8, p. 121-147, 2017.

BITENCOURT, Caroline Müller; RECK, Janriê Rodrigues. Interações entre direito fundamental à informação e democracia para o controle social: uma leitura crítica da LAl a partir da experiência dos portais de transparência dos municípios do rio grande do sul. Revista Direitos Fundamentais \& Democracia, UniBrasil, v. 23, p. 126-153, 2018.

BOBBIO, Norberto. A era dos direitos. Tradução Carlos Nelson Coutinho. Rio de Janeiro: Campus, 2004.

BONAVIDES, Paulo. Curso de direito constitucional. 6. ed. São Paulo: Malheiros, 1996.

BONAVIDES, Paulo. Teoria constitucional da democracia participativa: por um Direito Constitucional de luta e resistência, por uma Nova Hermenêutica, por uma repolitização da legitimidade. São Paulo: Malheiros, 2001. 
CONTROLADORIA-GERAL DA UNIÃO. Disponível em: http://www.cgu.gov.br/Publicacoes/controle-social/arquivos/controlesocial2012.pdf. Acesso em: 30 maio 2019.

DIAS, Clarence. Educação em direitos humanos com estratégia para o desenvolvimento. In: CLAUDE, Richard P.; ANDREPOULOS, George (org.). Educação em Direitos Humanos para o século XXI. São Paulo: Edusp, 2007.

FIGUEIREDO, Vanusa da Silva; SANTOS, Waldir Jorge Ladeira dos. Transparência e controle social na administração pública. Revista Temas de Administração Pública, v. 8, n. 1, Araraquara, 2013. Disponível em: https://periodicos.fclar.unesp.br/temasadm/ article/view/6327/4715. Acesso em: 6 jun. 2019.

GRUMAN, Marcelo. Lei de Acesso à Informação: notas e um breve exemplo. In: Dossiê governabilidade, informação e fiscalização política. Revista Debates, Porto Alegre, v. 6, n. 3, 2012. Disponível em: http://seer.ufrgs.br/debates/article/view/34229. Acesso em: 6 jun. 2019.

GUERRA, Sidney. Direitos humanos: curso elementar. São Paulo: Saraiva, 2013.

GÓMES, Santiago Roura. Alguns aspectos-chave do combate à corrupção na Administração Pública. In: MENDES, G. F.; BRANCO, P. G. G. SEMINÁRIO INTERNACIONAL DE DIREITO ADMINISTRATIVO E ADMINISTRAÇÃO PÚBLICA, 5., Tendências da Administração Pública. Escola de Administração de Brasília - IDP. Série IDP Eventos. Brasília, 2016.

GOMES, Wilson. A democracia digital e o problema da participação civil na decisão política. Revista Fronteiras, n. 7, 2005. Disponível em: http://revistas.unisinos.br/index.php/fronteiras/article/view/6394. Acesso em: 6 jun. 2019.

GOMES, Wilson. Democracia digital: Que democracia? Disponível em: http://www.plataformademocratica.org/PDF/13906. pdf. Acesso em: 6 jun. 2019.

JACOBI, Pedro Roberto. Ampliação da cidadania e participação - desafios na democratização da relação poder público-sociedade civil no Brasil. Tese - Faculdade de Educação, São Paulo: Universidade de São Paulo, 2005. Disponível em: https://www. teses.usp.br/teses/disponiveis/livredocencia/48/tde-25102005-105004/pt-br.php. Acesso em: 10 jun. 2019.

LEAL, Rogério Gesta. Efeitos predatórios da corrupção no mercado e na sociedade civil: alguns indicadores. Revista Brasileira de Estudos Políticos, v. 116, 2018.

LEAL, Rogério Gesta. Patologias corruptivas nas relações entre Estado, administração pública e sociedade: causas, consequências e tratamentos. Santa Cruz do Sul: Edunisc, 2013.

MORAES, Alexandre de. Direito constitucional. 28. ed. São Paulo: Atlas, 2012.

OBSERVATÓRIO SOCIAL DO BRASIL. Disponível em: http://osbrasil.org.br/o-que-e-um-observatorio-social-os/. Acesso em: 10 jun. 2019.

PEDROSA, Ronaldo Leite. Direito em história. 6. ed. Rio de Janeiro: Lumen Juris, 2010.

PEREIRA, José Matias. Reforma do Estado e controle da corrupção no Brasil. Caderno de Pesquisas em Administração, São Paulo, v. 12, n. 2, p. 1-17, abr/jun. 2005. Disponível em: https://repositorio.unb.br/bitstream/10482/919/1/ARTIGO_ReformaEstadoControle.pdf. Acesso em: 10 jun. 2019.

PÉREZ, Jesús Gonzáles. Corrupción, ética y moral en las administraciones públicas. 2. ed. España: Thomson Reuters, 2014.

TCE-RS. Tribunal de Contas do Estado do Rio Grande do Sul. 2018. Disponível em: http://portal.tce.rs.gov.br/docs/transparencia_2017/relatorio_transparencia_2017.pdf. Acesso em: 10 jun. 2019.

TCE-RS. 2019. Disponível em: http://portal.tce.rs.gov.br/docs/transparencia_2018/relatorio_transparencia_2018.pdf. Acesso em: 10 jun. 2019.

SANTOS, Antonio Raimundo dos. Metodologia científica: a construção do conhecimento. Rio de Janeiro: DP\&A Editora, 2001. SIMÃO NETO, Calil. Improbidade administrativa: teoria e prática: de acordo com a Lei no 12.846 de 10 de agosto de 2013, com a lei complementar no 135 de junho de 2010: Ficha Limpa. 2. ed. Leme: J. H. Mizuno, 2014. 